\title{
Matrix Infrared, $a b$ initio and Normal Coordinate Study of the Association of Methanol, Considering Especially the Torsional Mode in Nitrogen and Carbon Monoxide Matrices
}

\author{
JUHANI MURTO, MARKKU RÄSÄNEN, ANTERO ASPIALA and EERO KEMPPINEN
}

Department of Physical Chemistry, University of Helsinki, Meritullinkatu 1 C, SF-00170 Helsinki 17, Finland

IR spectra of $\mathrm{CH}_{3} \mathrm{OH}, \mathrm{CH}_{3} \mathrm{OD}$ and $\mathrm{CD}_{3} \mathrm{OD}$ in $\mathrm{N}_{2}$ matrices and of $\mathrm{CH}_{3} \mathrm{OH}$ in $\mathrm{CO}$ matrices have been recorded in order to study the association of methanol. $A b$ initio STO-3G calculations have been carried out on open and cyclic dimers and trimers. Approximate normal coordinate GVFF calculations, based on the appropriately scaled $a b$ initio force constants, have been carried out on open dimers and open and cyclic trimers. For the first time, a fine structure is found in the matrix IR spectrum of the $\mathrm{OH}$ torsional region of an alcohol, and is interpreted with the aid of the calculations. The results can be explained in terms of non-cyclic associates. In $\mathrm{N}_{2}$ spectra the monomer $\tau \mathrm{OH}$ band is at $304 \mathrm{~cm}^{-1}$, the dimer end group bands are at $386-325 \mathrm{~cm}^{-1}$, the trimer end group bands at $c a .500 \mathrm{~cm}^{-1}$, the dimer proton donor bands at $623-571 \mathrm{~cm}^{-1}$, and the trimer and polymer proton donor bands at $800-700 \mathrm{~cm}^{-1}$. The $\textrm{OH}$ and $\tau \mathrm{OH}$ dimer fine structures are proposed to be related to the different positions of the methanol molecules around the $\mathrm{O} \cdots \mathrm{O}$ axis. In $\mathrm{CO}$ only two non-cyclic dimer species were found, which interconvert reversibly in the temperature range $13-30 \mathrm{~K}$. The IR-induced interconversion of the dimers in matrices is discussed, considering the possibility of cyclic intermediates.

There are several studies dealing with the matrix IR spectra of methanol, ${ }^{1-10}$ the first paper being the classical one by Pimentel's group. ${ }^{1}$ Barnes and Hallam ${ }^{2}$ studied the association of methanol in argon, and they interpreted their results in terms of open chain dimers, trimers and tetra- mers, and cyclic tetramers, and dealt especially with the $\textrm{OH}, \delta \mathrm{OH}$ and $\downarrow \mathrm{CO}$ regions. The influence of association on the $\tau \mathrm{OH}$ (torsion) band was not studied, obviously because of the low intensity of this band in argon.

Schriver et al. ${ }^{8}$ made a thorough study of the $\mathrm{WH}$ dimer region of methanol in nitrogen matrices. Four different $\mathrm{VH}$ proton donor bands (called $D_{2}$ bands) were observed, together with the corresponding proton acceptor dimer end group bands ( $D_{1}$ bands) near the monomer $\mathrm{OH}$ peak (see Table 1), which proves conclusively that the methanol dimers are largely open (non-cyclic) in $\mathrm{N}_{2}$ matrices. Using temperatures down to $8 \mathrm{~K}$ and a spectrophotometer whose IR beam is monochromatic at the sample, they found in $\mathrm{N}_{2}$ (but not in Ar) both temperaturedependent and irradiation dependent processes. Upon increasing the temperature from 8 to $10 \mathrm{~K}$, species A (see Table 1) was converted to species

Table 1. The open methanol dimers: $\mathrm{OH}$ wavenumbers (in $\mathrm{cm}^{-1}$ ) in the IR spectrum for four species in nitrogen matrices at $8 \mathrm{~K}^{8}$

Ref. 8

\begin{tabular}{|c|c|c|c|}
\hline Species & $D_{1}$ & $D_{2}$ & \\
\hline $\begin{array}{l}\text { A } \\
\text { B } \\
\text { C } \\
\text { D }\end{array}$ & $\begin{array}{l}3655.2 \\
3651.0 \\
3658.7 \\
3654.1\end{array}$ & $\begin{array}{l}3519.5 \\
3504.0 \\
3496.0 \\
3488.8\end{array}$ & $\left.\begin{array}{l}\text { Ic } \\
\text { Ia }\end{array}\right\}$ Ib \\
\hline
\end{tabular}


B in a fast process; upon irradiation with broad band radiation, or with radiation of frequency $3489 \mathrm{~cm}^{-1}$ (the $\mathrm{OH}$ value of the proton donor band of species $D$ ), the amount of the $A$ and $B$ species increased in the matrix. In the case of $\mathrm{CH}_{3} \mathrm{OD}$, the broad-band IR-induced process was ten times slower than the corresponding process of $\mathrm{CH}_{3} \mathrm{OH}$. It was found also that the majority of the mixed dimers has the structure $\mathrm{CH}_{3} \mathrm{OD} \cdots \mathrm{O}(\mathrm{H}) \mathrm{CH}_{3}$.

We found two groups of sharp $\tau \mathrm{OH}$ association bands in our preliminary matrix IR study of methanol in $\mathrm{N}_{2}$ and $\mathrm{CO}$ matrices, ${ }^{9}$ one group (obviously due to end groups of open associates) being near the monomer band, and the other group at $600-800 \mathrm{~cm}^{-1}$. These findings prompted us to carry out $a b$ initio STO-3G calculations on methanol dimers and trimers, and to carry out normal coordinate calculations based on the diagonal force constants thus obtained. The purpose was to find support for the assignments of the $\mathrm{TOH}$ association bands, and to find an explanation for the quadruplet band structures of the dimer absorptions. The results are given in the present paper.

Methanol has no intramolecular absorption bands below $1000 \mathrm{~cm}^{-1}$ other than the $\tau \mathrm{OH}$ band, and since the molecule is small, it perturbs the matrix lattice only little. ${ }^{10}$ Thus it is an ideal molecule for studying and calculating the association structure in the $\tau \mathrm{OH}$ region.

In a separate paper ${ }^{10}$ we have discussed the specific influence of $\mathrm{N}_{2}$ and $\mathrm{CO}$ on the $\mathrm{OH}$, $\delta \mathrm{OH}, \downarrow \mathrm{CO}$ and $\tau \mathrm{OH}$ bands of monomeric methanol.

Association $\tau \mathrm{OH}$ bands of alcohols. Surprisingly little is known about the influence of association or heterodimer formation on the torsional vibration of alcohols. ${ }^{11-19}$ Liquid alcohols display an extremely broad $\tau \mathrm{OH}$ band near $650 \mathrm{~cm}^{-1}$, with a half-width of $200-300 \mathrm{~cm}^{-1} .{ }^{12}$ In the case of liquid $\mathrm{CH}_{3} \mathrm{OH}$ the band occurs in the range $450-850 \mathrm{~cm}^{-1}$, and in the case of $\mathrm{CH}_{3} \mathrm{OD}$ in the range $350-630 \mathrm{~cm}^{-1} \cdot{ }^{11,13}$ In the spectra of liquid ethanol the band is centred at $660 \mathrm{~cm}^{-1}$, whereas in the spectra of crystalline ethanol a triplet with peaks at 725,750 and $790 \mathrm{~cm}^{-1}$ is observed. ${ }^{14}$

In matrix spectra of alcohols at high concentra-
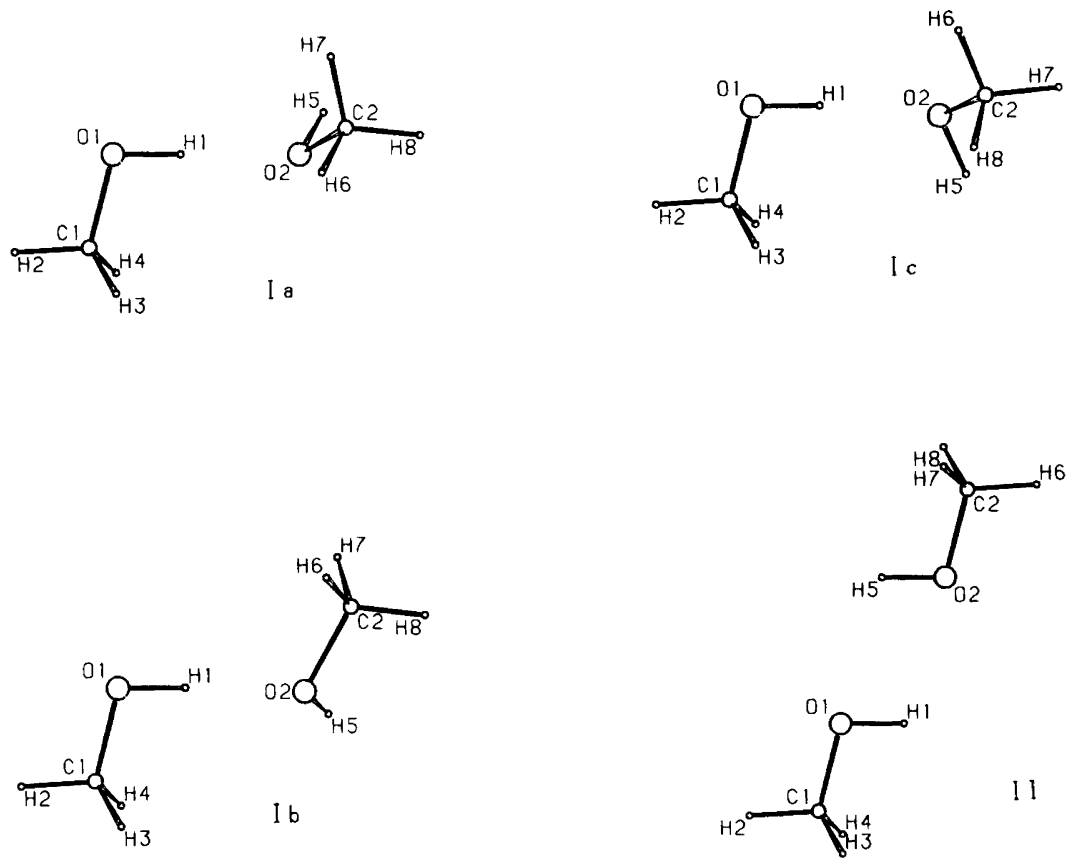

Fig. 1. Computer-drawn pictures of the optimized methanol dimers. Structures $\mathrm{Ia}$, Ib and $\mathrm{Ic}^{\prime}$ are open species (see Table 2); structure II is the cyclic dimer, for which $\Delta E=-7.1 \mathrm{~kJ} \mathrm{~mol}^{-1}$, and the optimized values of the coordinates are: $\mathrm{OH} 99.02 \mathrm{pm}, \mathrm{CO} 143.2 \mathrm{pm}, \mathrm{OO} 285 \mathrm{pm}, \mathrm{COH} 104.2^{\circ}$ and COO $158.3^{\circ}$. 
tions the association (polymer) $\tau \mathrm{OH}$ band is usually similar to those in the spectra of liquids, i.e., it is a broad, indeterminate, structureless band at $600-700 \mathrm{~cm}^{-1} \cdot{ }^{18,19}$ Thus it often remains unnoticed unless the concentration of the alcohol is quite high. There do not seem to exist cases where $\tau \mathrm{OH}$ dimer bands of alcohols in matrices have previously been definitely assigned.

Previous calculations on methanol dimers and trimers. There exist a few ab initio calculations ${ }^{20-24}$ and one EPEN (empirical potential using electrons and nuclei) calculation ${ }^{25}$ on methanol associates. The calculations have been carried out with rigid monomer geometries. The STO-3G dimerization energy of the open dimer (corresponding to structure Ia in Fig. 1) is -23.3 $\mathrm{kJ} \mathrm{mol}^{-1} \cdot{ }^{20,23}$ The cyclic dimer is considerably less stable, and an STO-3G dimerization energy of $-9.0 \mathrm{~kJ} \mathrm{~mol}^{-1}$ has been reported. ${ }^{22}$

The ab initio STO-3G geometries and energies of trimers and higher associates up to hexamers have been estimated ${ }^{24}$ on the basis of water polymer structures. In the case of trimers, the cyclic structure was found to be more stable than the lowest-energy open structure (the energies of formation from the monomers being -64.2 and $-55.5 \mathrm{~kJ} \mathrm{~mol}^{-1}$, respectively). The third type of trimers is the "double acceptor" species, the energy obtained for it being $-37.5 \mathrm{~kJ} \mathrm{~mol}^{-1}$. $^{24}$ EPEN calculations ${ }^{25}$ yield similar energies as the STO-3G calculations for all of these trimers.

\section{EXPERIMENTAL}

The matrix IR measurements were carried out as previously, ${ }^{18}$ using a Perkin-Elmer 621 spectrophotometer and a Displex CS-202 cryocooler. $\mathrm{CH}_{3} \mathrm{OH}$ (E. Merck A.G., pro analysi), $\mathrm{CH}_{3} \mathrm{OD}$ (Fluka A.G., purum) and $\mathrm{CD}_{3} \mathrm{OD}$ (Fluka A.G., puriss.) were commercial products; they were dried with molecular sieves. The deposition temperature was $15 \mathrm{~K}$; the heating and cooling rate of the matrices was $0.5 \mathrm{~K} \mathrm{~min}^{-1}$ ( $c f$. Ref. 5). The lowest recording temperature was $13 \mathrm{~K}$. The matrices were annealed by warming them $2-3 \mathrm{~K}$ above the highest recording temperature.

\section{$A b$ initio CALCULATIONS}

The $a b$ initio calculations were carried out as previously described, ${ }^{26}$ using the programme Gaussian 76 and the minimal STO-3G basis. By

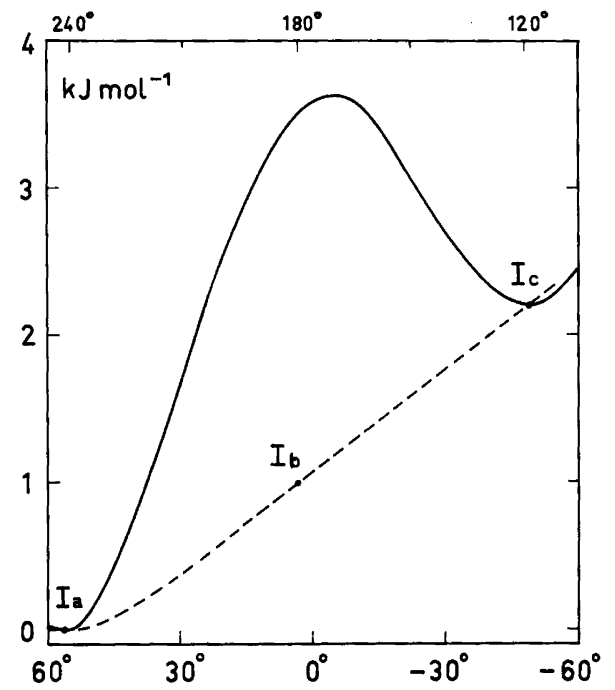

Fig. 2. STO-3G energies for the open methanol dimers: rotation of the second methanol molecule around the $\mathrm{O} \cdots \mathrm{O}$ axis (broken line, upper scale) and around the $\mathrm{C}_{2} \mathrm{O}_{2}$ bond (solid line, lower scale).

using this relatively small basis it was possible to optimize also the trimer structures. All intermolecular coordinates of the methanol associates, as well as intramolecular coordinates that relate to the $\mathrm{COH}$ groups of the methanol units, were carefully optimized by the usual iterative technique.

The four methanol dimer structures shown in Fig. 1 were optimized. For the structures $\mathrm{Ia}, \mathrm{Ib}$ and Ic the dihedral angle $\tau_{4}\left(\mathrm{C}_{1} \mathrm{O}_{1} \mathrm{O}_{2} \mathrm{C}_{2}\right)$ of the open dimer is $-118^{\circ}$ (or $242^{\circ}$ in Fig. 2), $180^{\circ}$ (planar $\mathrm{C}_{1} \mathrm{O}_{1} \mathrm{O}_{2} \mathrm{C}_{2}$ arrangement) and $118^{\circ}$, respectively. Structure Ia represents the total energy minimum of all methanol dimers, whereas structures Ib and Ic do not correspond to energy minima (with respect to $\tau_{4}$ ); they were included to study the influence of variations in $\tau_{4}$ on the total energy of the dimer. Structure $I c^{\prime}$ is the spectroscopically and energetically equivalent mirror image of structure Ic. Data on structures Ia and Ic are given in Table 2 (Del Bene ${ }^{20}$ has reported values for quite different coordinates).

A picture and data on the cyclic dimer (structure II) are given in Fig. 1. This is the "planar" dimer ${ }^{22}$ of $C_{2 h}$ symmetry.

Fig. 2 represents the variation of the STO-3G 
Table 2. Ab initio STO-3G and normal coordinate results for the open dimers Ia and Ic. Units: bond lengths in picometres, angles in degrees, wavenumbers in $\mathrm{cm}^{-1}$, stretching force constants in mdyn $\AA^{-1}=10^{2} \mathrm{~N} \mathrm{~m}^{-1}$, bending and torsion force constants in mdyn $\AA \operatorname{rad}^{-2}=\mathrm{aN} \mathrm{m} \mathrm{rad}{ }^{-2}$.

\begin{tabular}{|c|c|c|c|c|c|c|c|}
\hline & \multirow[t]{2}{*}{ Coord. } & \multicolumn{2}{|c|}{$\begin{array}{l}\text { Opt. coord. Force } \\
\text { value } \\
\text { const. }\end{array}$} & $\left.v_{\text {calc. }}{ }^{\mathrm{PED}}\right)^{a}$ & $\begin{array}{l}\text { Opt. coord. } \\
\text { value }\end{array}$ & $\begin{array}{l}\text { Force } \\
\text { const. }\end{array}$ & $\begin{array}{l}v_{\text {calc. }} \\
(\mathrm{PED})^{a}\end{array}$ \\
\hline & & \multicolumn{2}{|c|}{ Structure Ia } & \multicolumn{3}{|c|}{ Structure Ic } & \multirow{4}{*}{$\begin{array}{l}3501(98) \\
3656(100)\end{array}$} \\
\hline \multirow{3}{*}{$\begin{array}{l}v_{1} \\
v_{2} \\
v_{3}\end{array}$} & $\mathrm{O}_{1} \mathrm{H}_{1}$ & 99.22 & $9.937^{b, c}$ & \multirow{4}{*}{$\begin{array}{l}3490(98) \\
3659(100) \\
1048(87) \\
1064(55) \\
1044(42)\end{array}$} & 99.22 & \multirow{4}{*}{$\begin{array}{l}10.001^{b, d} \\
10.077^{b}\end{array}$} & \\
\hline & $\mathrm{O}_{2} \mathrm{H}_{5}$ & 98.92 & 10.094 & & 98.95 & & \\
\hline & $\mathrm{C}_{1} \mathrm{O}_{1}$ & 142.9 & 8.178 & & 142.9 & & \\
\hline$v_{4}$ & $\mathrm{C}_{2} \mathrm{O}_{2}$ & 143.4 & 8.211 & & 143.4 & & \\
\hline$\delta_{1}$ & $\mathrm{C}_{1} \mathrm{O}_{1} \mathrm{H}_{1}$ & 104.1 & 1.54 & $1386(69)$ & 104.1 & & \\
\hline$\delta_{2}$ & $\mathrm{C}_{2} \mathrm{O}_{2} \mathrm{H}_{5}$ & 104.8 & 1.34 & $1325(65)$ & 104.8 & & \\
\hline$\tau_{1}$ & $\mathrm{H}_{2} \mathrm{C}_{1} \mathrm{O}_{1} \mathrm{H}_{1}$ & 180.0 & 0.320 & $625(91)$ & 180.1 & 0.290 & $597(92)$ \\
\hline$\tau_{2}$ & $\mathrm{H}_{6} \mathrm{C}_{2} \mathrm{O}_{2} \mathrm{H}_{5}$ & 180.1 & 0.103 & $385(94)$ & 180.0 & 0.092 & $361(95)$ \\
\hline$v_{5}$ & $\mathrm{O}_{1} \mathrm{O}_{2}$ & 274 & 0.336 & $192(79)$ & 275 & & \\
\hline$\delta_{3}$ & $\mathrm{C}_{1} \mathrm{O}_{1} \mathrm{O}_{2}$ & 103.9 & 0.193 & $85(76)$ & 101.1 & & \\
\hline$\delta_{4}$ & $\mathrm{O}_{1} \mathrm{O}_{2} \mathrm{C}_{2}$ & 117.4 & 0.086 & $65(84)$ & 117.8 & & \\
\hline$\tau_{3}$ & $\mathrm{H}_{2} \mathrm{C}_{1} \mathrm{O}_{1} \mathrm{O}_{2}$ & 180.8 & 0.228 & $220(89)^{e}$ & -178.2 & & \\
\hline$\tau_{4}$ & $\mathrm{C}_{1} \mathrm{O}_{1} \mathrm{O}_{2} \mathrm{C}_{2}$ & -117.6 & 0.003 & $18(99)$ & $\left(118^{f}\right)$ & & \\
\hline$\tau_{5}$ & $\mathrm{O}_{1} \mathrm{O}_{2} \mathrm{C}_{2} \mathrm{H}_{6}$ & 56.3 & 0.044 & $108(91)$ & 47.9 & & \\
\hline \multirow{2}{*}{\multicolumn{2}{|c|}{$\begin{array}{l}-\Delta E /\left(\mathrm{kJ} \mathrm{mol}^{-1}\right)^{g} \\
\mu / \mathrm{D}^{h}\end{array}$}} & 23.5 & & & 21.3 & & \\
\hline & & 2.91 & & & 3.45 & & \\
\hline
\end{tabular}

a The major potential energy contribution is due to the internal coordinate in question; the per cent value is given within parentheses. ${ }^{b}$ The distance $\mathrm{H}_{1} \mathrm{O}_{2}$ was kept constant. ${ }^{c}$ The angle $\mathrm{O}_{1} \mathrm{H}_{1} \mathrm{O}_{2}$ is $179.6^{\circ}$, the dihedral angle $\mathrm{C}_{1} \mathrm{O}_{1} \mathrm{H}_{1} \mathrm{O}_{2}$ is $0.4^{\circ}$. ${ }^{d}$ The angle $\mathrm{O}_{1} \mathrm{H}_{1} \mathrm{O}_{2}$ is $176.1^{\circ}$, the dihedral angle $\mathrm{C}_{1} \mathrm{O}_{1} \mathrm{H}_{1} \mathrm{O}_{2}$ is $-14.2^{\circ}$. . Value 0 for the coupling constant $\tau_{1} / \tau_{3}$ gives $221(88)$, value -0.10 mdyn $\AA$ gives $177(68) .{ }^{f}$ Not an energy minimum. ${ }^{g}$ The dimerization energy. The energy of the optimized monomer is -113.549190 a.u. ${ }^{h}$ The calculated dipole moment in Debye units. $1 \mathrm{D}=3.335 \times 10^{-30} \mathrm{C} \mathrm{m}$.

Table 3. STO-3G optimized geometries for methanol trimers. See Table 2 for the units.

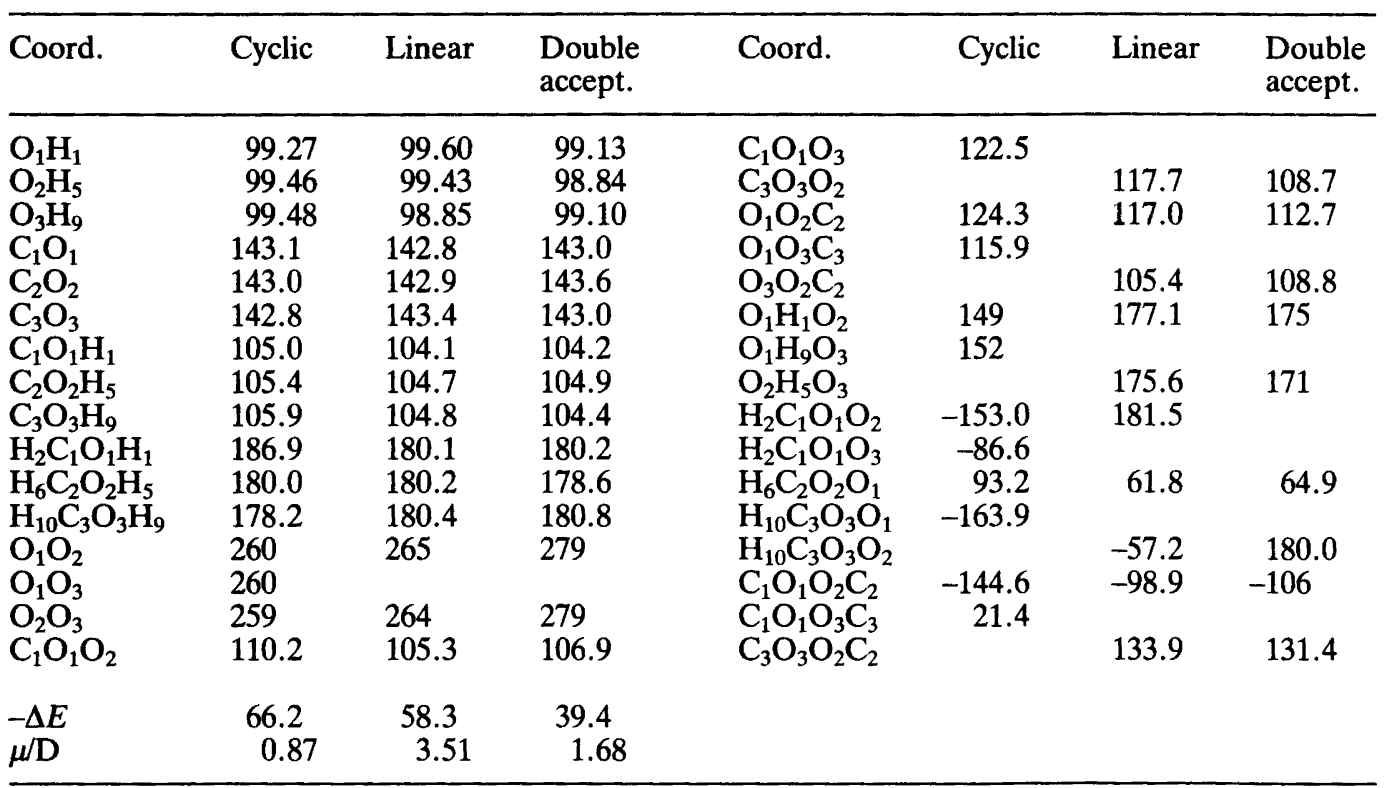


dimerization energy when rotating the second methanol molecule with respect to the first. The rotation $\mathrm{Ia} \rightarrow \mathrm{Ic}^{\prime}$ around the $\mathrm{C}_{2} \mathrm{O}_{2}$ bond (with respect to $\tau_{5}$ ) involves a flat maximum ${ }^{22}$ at $\tau_{5} \mathrm{ca}$. $0^{\circ}$. The rotation around the $\mathrm{O}_{1} \mathrm{O}_{2}$ axis (in terms of $\tau_{4}$ ) froom structure Ia to structure Ic involves an almost linear increase in energy, by $c a .2 .2 \mathrm{~kJ}$ $\mathrm{mol}^{-1}$.

The geometries of the three trimers were optimized (Table 3). In addition to the most stable species, the cyclic trimer (the same as in Ref. 25), also the double acceptor structure (open species I in Ref. 24) and an open "linear" structure (species II ${ }^{24}$ ) were optimized. The double acceptor species has a high energy compared to both the cyclic and linear species. However, matrices represent non-equilibrium systems, and also structures representing local energy minima may be formed (at least during diffusion within matrices). This was the reason for including the double acceptor structure in the calculations.

The trimer formation energies obtained (Table 3) are surprisingly similar to those found by Curtiss ${ }^{24}$ without optimizations. Pictures of the cyclic and double acceptor species can be found in the literature. ${ }^{25}$

According to the calculations, the $\mathrm{OH}$ bond length increases upon $\mathrm{H}$-bond formation from its optimized value in the monomer $(99.12 \mathrm{pm}$; Table 4); in the free end group the bond is shorter than in the monomer. The calculated value of the $\mathrm{COH}$ angle increases in all cases from the value in the monomer, the increase being most marked in the strained cyclic trimer. The $\mathrm{CO}$ bond length changes only little from the monomer value upon association. The angles $\mathrm{O}-\mathrm{H} \cdots \mathrm{O}$ differ slightly from $180^{\circ}$ in the noncyclic dimers and trimers.

Values for the diagonal force constants were also obtained for all optimized coordinates ( $c f$. also Ref. 26). Their values for the open dimer species are given in Table 2.

\section{NORMAL COORDINATE CALCULATIONS}

The normal coordinate calculations were carried out using the modified Schachtschneider programmes described previously. ${ }^{19}$ The torsional coordinate used was the simple trans dihedral angle $\mathrm{HCOH}$, since the STO-3G force constant was calculated for this coordinate.

The calculations were based on the general valence force field of methanol monomer by Timidei and Zerbi. ${ }^{27}$ Since the STO-3G geometries differ from the experimental geometries, the geometries used were based on the experimental data used by Timidei and Zerbi. For the $\mathrm{CH}_{3}$ group the force constants of Timidei and Zerbi were used for all associates. The same force field was used for the protium and deuterium compounds.

It is well known that the harmonic STO-3G force constants are considerably larger than the experimental values. Thus the calculated STO$3 \mathrm{G}$ force constants were reduced by constant factors ( $c f$. Ref. 28). The reduction factors used

Table 4. The $\mathrm{COH}$ vibrations of the $\mathrm{CH}_{3} \mathrm{OH}$ monomer, calculated according to Timidei and Zerbi, ${ }^{27}$ and according to the STO-3G calculations: evaluation of the force constant reduction factors. Units as in Table 2.

\begin{tabular}{|c|c|c|c|c|c|c|c|c|}
\hline & $\begin{array}{l}\text { Coord. } \\
\text { value }\end{array}$ & $\begin{array}{l}\text { Force } \\
\text { const. }\end{array}$ & $v_{\text {calc. }}$ & $\begin{array}{l}\text { Opt. } \\
\text { coord. } \\
\text { value }\end{array}$ & $\begin{array}{l}\text { Force } \\
\text { const. }\end{array}$ & $\begin{array}{l}\text { Force } \\
\text { constant } \\
\text { reduction } \\
\text { factor }\end{array}$ & $v_{\text {calc }}$ & $\begin{array}{l}v_{\exp _{.}}{ }^{10} \\
\text { in } \mathrm{N}_{2}\end{array}$ \\
\hline & \multicolumn{3}{|c|}{ Experimental ${ }^{27}$} & \multicolumn{2}{|l|}{ STO-3G } & & & \\
\hline WH & 95.6 & 7.623 & 3679 & 99.12 & 9.971 & $1.351^{a}$ & 3637 & 3665 \\
\hline$\delta \mathrm{OH}$ & 108.9 & 0.764 & 1339 & 103.9 & 1.387 & $1.815^{b}$ & 1339 & 1348 \\
\hline$\checkmark \mathrm{CO}$ & 142.7 & 5.221 & 1044 & 143.3 & 8.164 & $1.564^{b}$ & 1044 & 1035 \\
\hline$\tau \mathrm{OH}$ & 180 & $0.0342^{c, d}$ & 304 & 180 & 0.0649 & $1.90^{d}$ & 304 & 304 \\
\hline
\end{tabular}

\footnotetext{
${ }^{a}$ Adjusted to give the experimental value for the linear dimer end group. ${ }^{b}$ Adjusted to give the force constant given by Timidei and Zerbi. ${ }^{c}$ Calculated in this paper. ${ }^{d}$ Adjusted to give the experimental frequency.
} 
for $\mathrm{WH}, \delta \mathrm{OH}, \downarrow \mathrm{CO}$ and $\tau \mathrm{OH}$ vibrations of all dimers and trimers are given in Table 4 . The value 1.90 obtained for $\tau \mathrm{OH}$ was used also for all intermolecular force constants (note that the value 1.82 for $\delta \mathrm{OH}$ is close to this value).

To keep the number of adjustable parameters as low as possible, only two interaction force constants between the coordinates were used. An interaction constant between the $\mathrm{OH}$ and the corresponding $\mathrm{O} \cdots \mathrm{O}$ stretching coordinates is required. ${ }^{29}$ The value 0.383 mdyn $\AA^{-1}$ was used for it; the calculated $\mathrm{H}$-donor $\mathrm{WH}$ frequency of the open dimers then shifted downwards into the correct region, to $c a .3490 \mathrm{~cm}^{-1}$ in the case of species Ia (in the case of phenol-pyridine complexes the corresponding interaction constant was 0.3 mdyn $\AA^{-129}$ ).
A coupling constant of -0.05 mdyn $\AA$ was introduced in the case of the open dimers between the torsions $\tau_{1}$ and $\tau_{3}$; it shifted the bonded $\tau \mathrm{OH}$ frequency of species Ia from 641 to $625 \mathrm{~cm}^{-1}$ and improved the potential energy distribution (PED). This coupling constant was used also in the case of the double acceptor trimer. In the case of cyclic and linear trimers the value -0.10 mdyn $\AA$ was used, since the bonding is stronger than in the case of the open dimers.

\section{RESULTS AND DISCUSSION}

The experimental results are given in Table 5 and Figs. 3-7. Only the most important $\mathrm{WH}$, $\delta \mathrm{OH}$ and $\mathrm{WO}$ association bands are considered,

Table 5. The most important $\downarrow \mathrm{OH}, \delta \mathrm{OH}$ and $\mathrm{rO}$ bands for $\mathrm{CH}_{3} \mathrm{OH}$ and the $\tau \mathrm{OH}$ bands for $\mathrm{CH}_{3} \mathrm{OH}$, $\mathrm{CH}_{3} \mathrm{OD}$ and $\mathrm{CD}_{3} \mathrm{OD}$ in nitrogen matrix spectra. The letters $\mathrm{A}-\mathrm{D}$ refer to the species in Table 1 , the letter $\mathrm{E}$ to a proton acceptor end group. The wavenumbers are in $\mathrm{cm}^{-1}$.

\begin{tabular}{|c|c|c|c|c|c|}
\hline \multirow{2}{*}{$\begin{array}{l}\text { Wavenumber } \\
\mathrm{CH}_{3} \mathrm{OH}\end{array}$} & \multirow[t]{2}{*}{ Assignment } & \multicolumn{3}{|c|}{ Wavenumber } & \multirow{2}{*}{ Assignment } \\
\hline & & $\mathrm{CH}_{3} \mathrm{OH}$ & $\mathrm{CH}_{3} \mathrm{OD}$ & $\mathrm{CD}_{3} \mathrm{OD}$ & \\
\hline & & $\tau \mathrm{OH}$ & & & \\
\hline 3673 & $\operatorname{dim} . E$ & 795 & 581 & 580 & polym. \\
\hline $3665 \mathrm{~s}$ & monom. & 792 br & 570 br & $570 \mathrm{br}$ & polym. \\
\hline $3659-3488$ & dim., see Table 1 & $710-780$ & $520-560$ & $520-560$ & trim./tetram. \\
\hline 3445 & trim./tetram. & 644 & 478 & 478 & multim. E \\
\hline 3430 & trim./tetram. & 623 & 468 & 466 & $\operatorname{dim} . \mathrm{D}$ \\
\hline $3390^{a}$ & trim./tetram. & 609 & $457 \mathrm{vw}$ & $459 \mathrm{vw}$ & dim. \\
\hline 3371 & trim./tetram. & 593 & $446^{d}$ & $444^{d}$ & dim. B \\
\hline $3285 \mathrm{br}$ & polym. & 583 & $439^{c}$ & $438^{c}$ & $\operatorname{dim} . C$ \\
\hline 3240 & polym. & 571 & $429^{d}$ & $427^{d}$ & $\operatorname{dim} . A$ \\
\hline$\delta \mathrm{OH}$ & & 550 & 414 & 413 & water compl.? \\
\hline 1419 & polym. & 527 & 399 & 397 & trim./tetram. E \\
\hline 1397 & dim. & 512 & $377^{a}$ & 377 & trim. $\mathrm{E}$ \\
\hline 1360 & dim. & $485^{a}$ & 353 & 352 & trim. E \\
\hline $1348 \mathrm{~s}$ & monom. & 386 & ca. $300^{c, e}$ & $300^{c}$ & dim. E, D \\
\hline $1346 \mathrm{sh}$ & dim. E & $371 \mathrm{vw}$ & & & dim. \\
\hline 1344 & $\operatorname{dim} . E$ & 359 & $282^{c}$ & $278^{c}$ & $\operatorname{dim} . \mathrm{E}, \mathrm{C}$ \\
\hline $\mathrm{KO}$ & & $332^{b}$ & & & dim. E, A \\
\hline 1110 & polym. & $325^{a}$ & $263^{a, d}$ & $258^{d}$ & dim. E, B \\
\hline 1051 & dim. & $304 \mathrm{~s}$ & $246 \mathrm{~s}$ & $239 \mathrm{~s}$ & monom. \\
\hline $1040^{b}$ & dim. & & & & \\
\hline 1035 vs & monom. & & & & \\
\hline 1032 & dim. $E$ & & & & \\
\hline $1029^{a}$ & $\operatorname{dim} . \bar{E}$ & & & & \\
\hline
\end{tabular}

\footnotetext{
${ }^{a}$ Maximum intensity decreases reversibly upon warming from 13 to $20 \mathrm{~K}$ (not indicated for all bands of this type). ${ }^{b}$ Relative band intensity increases reversibly upon warming. ${ }^{c}$ Band intensity decreases upon irradiation. ${ }^{d}$ Band intensity increases upon irradiation. ${ }^{e}$ The band is superposed on the monomer band of the protium compound.
} 


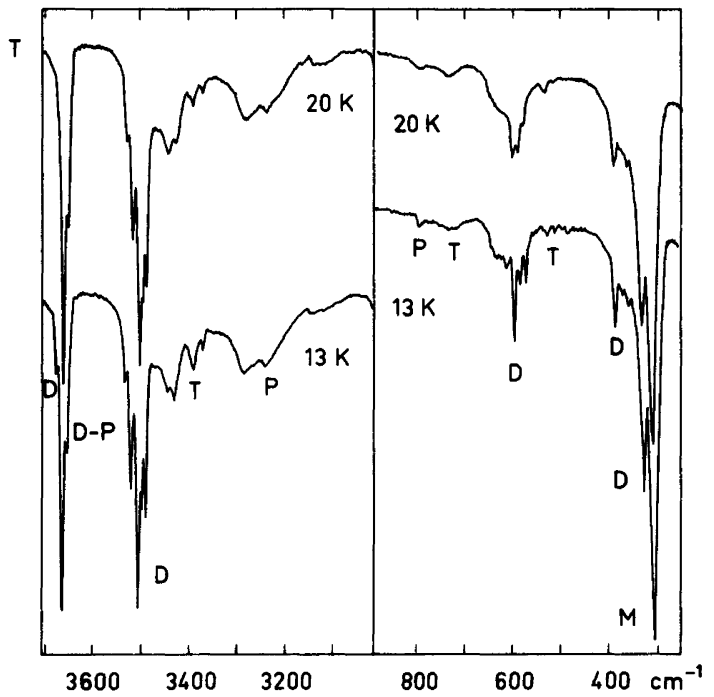

Fig. 3. The $\mathrm{OH}$ and $\tau \mathrm{OH}$ regions of $\mathrm{CH}_{3} \mathrm{OH}$ in $\mathrm{N}_{2}, \mathrm{M} / \mathrm{A}=100$ : influence of temperature. $\mathrm{M}=$ monomer, $\mathrm{D}=$ dimer, $\mathrm{T}=$ trimer $/$ tetramer, $\mathrm{P}=$ polymer.

and are assigned analogously to the argon results. $^{2}$

The $v O H$ mode. It is significant that the $\mathrm{WH}$ dimer $\mathrm{D}_{2}$ bands in $\mathrm{N}_{2}$ are quite sharp at low temperatures and concentrations $\left(\Delta v_{1 / 2} \approx 5 \mathrm{~cm}^{-1}\right)$. Thus, in addition to monomers, ${ }^{10}$ dimers do not perturb the $\mathrm{N}_{2}$ lattice significantly.
Schriver et $a l .^{8}$ considered multiple site trapping as an explanation for the quartet nature of the dimer $\mathrm{D}_{2} \mathrm{WH}$ band, although it is observed both in $\mathrm{Ar}$ and $\mathrm{N}_{2}$ spectra. Since the STO-3G energy of the dimer changes only little when varying the dihedral angle $\mathrm{C}_{1} \mathrm{O}_{1} \mathrm{O}_{2} \mathrm{C}_{2}$ (see Fig. 2), and simultaneously there are significant changes

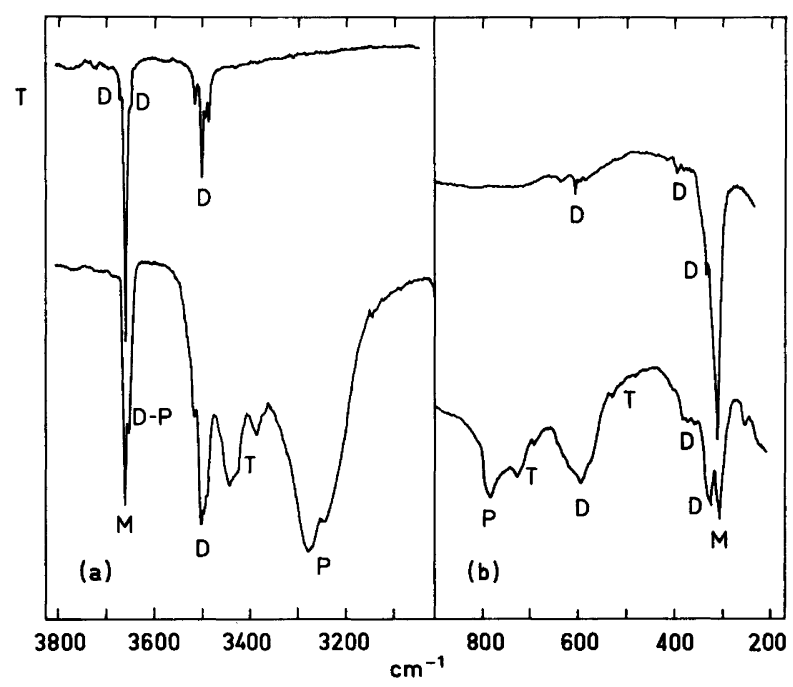

Fig. 4. The $\mathrm{OH}$ and $\tau \mathrm{OH}$ regions of $\mathrm{CH}_{3} \mathrm{OH}$ in $\mathrm{N}_{2}$, temperature $13 \mathrm{~K}$; influence of concentration. Upper curves: $M / A=250$, lower curves: $M / A=20$.

Acta Chem. Scand. A 37 (1983) No. 4 


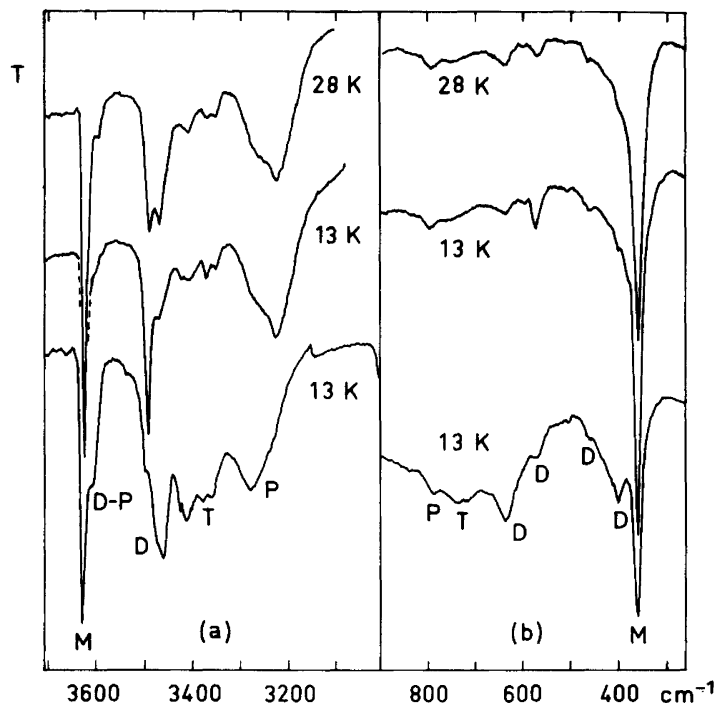

Fig. 5. The $\mathrm{OH}$ and $\tau \mathrm{OH}$ regions of $\mathrm{CH}_{3} \mathrm{OH}$ in $\mathrm{CO}$. The two upper curves: $\mathrm{M} / \mathrm{A}=100$, annealed to 30 $K$; the lowest curves: $M / A=20$, unannealed (warming decreases the end group band at $400 \mathrm{~cm}^{-1}$ and increases the $\mathrm{P}$ bands considerably in the latter case).

in the $\mathrm{OH}$ and $\tau \mathrm{OH}$ force constants, we conclude that the multiplet structures of the $\mathrm{WH}$ dimer association bands are due to several different mutual positions of the two methanol molecules relative to the $\mathrm{O} \cdots \mathrm{O}$ axis. Only one of these positions (Ia) corresponds to an energy minimum in vapour; in matrices the other positions are stabilized by substitutional site effects. Interactions with the matrix molecules (see below) may change the relative energies of the species.

Inspection of the calculated $\mathrm{WH}$ values given in Table 2 shows that the change $\mathrm{Ia} \rightarrow \mathrm{Ic}$ is accompanied by a small decrease of the ${ }^{\circ H} D_{1}$ (end group) frequency $v_{2}$ and by a somewhat larger increase of the $\mathrm{D}_{2} \mathrm{WH}$ frequency $v_{1}$ (these changes are continuous in the sequence $\mathrm{Ia}$ to $\mathrm{Ib}$ to Ic). The distance $\mathrm{O} \cdots \mathrm{O}$ increases and the bond weakens slightly during the rotation $\mathrm{Ia} \rightarrow \mathrm{Ic}$.

The observed ${ }^{8}$ thermal process, species $A \rightarrow$ species B, occurs largely between 8 and 10 $\mathrm{K}$, i.e., in a narrow temperature range, like phase transition processes; ${ }^{8}$ this process in $\mathrm{N}_{2}$ is not considered in the present paper. Our experimental results indicate that above $13 \mathrm{~K}$ (our lowest attainable temperature) the major influence of temperature on the $\mathrm{vOH} \mathrm{D}_{2}$ bands is a broadening of the bands, together with a slight decrease of the maximum absorbance. Thus it seems probable that considerable barriers are involved in the interconversion between the "sites".

There are interactions (more or less specific ${ }^{10}$ ) between the dimers and the matrix lattice, and their influence is seen especially in the $\tau \mathrm{OH}$ region (see below). Thus it is not possible to establish a direct correspondence between the species $A-D$ in Table 1 and the species Ia-Ic discussed above. However, we propose an appoximate correspondence as shown in Table 1. Thus there is at least a qualitative agreement between experiments and the calculations.

Only two interconverting $\mathrm{WH}$ proton donor dimer bands were found in the spectra of methanol in well-annealed $\mathrm{CO}$ matrices (see Fig. 5). The band at $3498 \mathrm{~cm}^{-1}$ decreases and that at $3478 \mathrm{~cm}^{-1}$ increases with increasing temperature; these will be called $A$ and $B$ type bands, respectively. The energy difference $\Delta H$ between the corresponding species is $c a .300-400 \mathrm{~J} \mathrm{~mol}^{-1}$, as determined from the variation of the peak heights with temperature. Obviously the sites in $\mathrm{CO}$ are quite different from those in $\mathrm{Ar}$ or $\mathrm{N}_{2}$, and the strong interactions with the polar $\mathrm{CO}$ matrix molecules may dominate ( $c f$. Ref. 10). The bands are broader than those in $\mathrm{N}_{2}$, especial- 


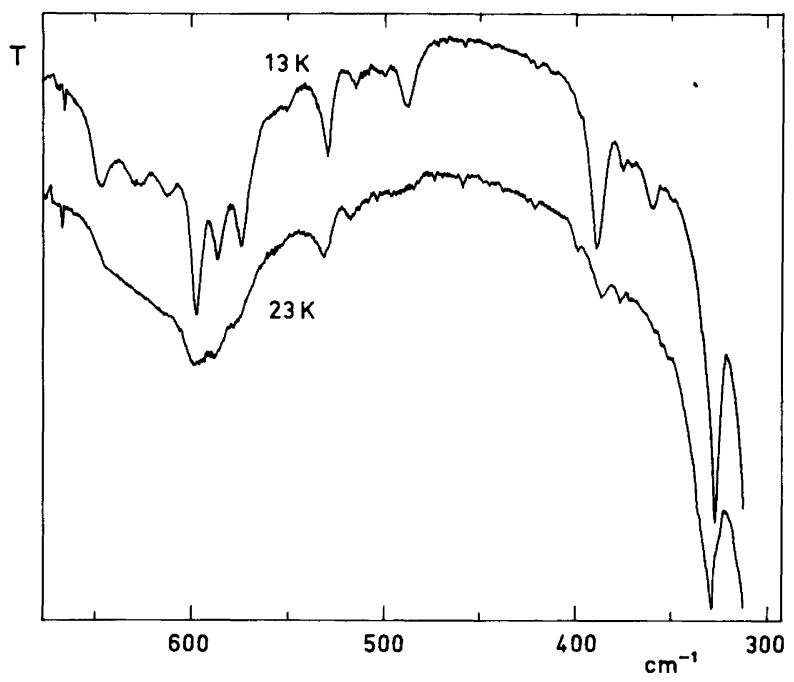

Fig. 6. Part of the $\tau \mathrm{OH}$ region of $\mathrm{CH}_{3} \mathrm{OH}$ in $\mathrm{N}_{2}, \mathrm{M} / \mathrm{A}=100$, recorded at two temperatures.

ly the lower-frequency band (in unannealed matrices it has a shoulder at $3460 \mathrm{~cm}^{-1}$ ). The end-group $\left(D_{1}\right)$ bands are obviously at $3618 \mathrm{~cm}^{-1}$ (A) and $\mathrm{ca}$. $3595 \mathrm{~cm}^{-1}(B)$, indicating that the dimers are non-cyclic (see also Fig. 5).

It can be concluded that the changes corresponding to those which Schriver et al. ${ }^{8}$ observed in $\mathrm{N}_{2}$ between 8 and $10 \mathrm{~K}$ occur in $\mathrm{CO}$ at considerably higher temperatures.

The $\tau(O D)$ bands in $N_{2}$. The correspondence between the $\tau \mathrm{OH}$ and $\mathrm{WH}$ regions is shown in Figs. 3 and 4, and details of the $\tau \mathrm{OH}$ region in Fig. 6.

The monomer band is at $304 \mathrm{~cm}^{-1}$ in $\mathrm{N}_{2}$ matrix spectra. It is strongly and reversibly temperature dependent. $^{10}$

The dimer $\tau \mathrm{OH}$ end group $\left(D_{1}\right)$ bands are in the region $386-325 \mathrm{~cm}^{-1}$, and the proton donor $\left(D_{2}\right)$ bands in the region $623-572 \mathrm{~cm}^{-1}$ (see, e.g., the upper curves in Fig. 4, and the results of the $a b$ initio calculations). After the initial irradiation the most intense dimer peaks are those at 325 and $593 \mathrm{~cm}^{-1}$.

There seem to be five $\tau \mathrm{OH}$ dimer $D_{2} / D_{1}$ pairs in the spectra of $\mathrm{CH}_{3} \mathrm{OH}$ (Fig. 6, Table 5; the sixth band at $644 \mathrm{~cm}^{-1}$ in the $D_{2}$ group is due to multimers). The fifth $D_{2}$ band (at $459 \mathrm{~cm}^{-1}$ in Fig. 7) is weak in the spectra of the OD compounds. Since the conversions due to irradiation are slow also in the case of $\mathrm{CD}_{3} \mathrm{OD}$, it was possible to establish a correspondence between the $\tau \mathrm{OH}$ and $\mathrm{OH}$ dimer fine structures (see Table 5).

To obtain some indication of the magnitude of the specific interaction between nitrogen and methanol, an STO-3G/normal coordinate calculation was carried out with an $\mathrm{N}_{2}$ molecule bonded to $\mathrm{H}_{5}$ of species Ia (linear $\mathrm{O}_{2} \mathrm{H}_{5} \mathrm{NN}$ arrangement $\left.{ }^{10}\right)$. The $\tau_{2}$ frequency was then shifted from $385 \mathrm{~cm}^{-1}$ to $436 \mathrm{~cm}^{-1}$. Thus it is seen that such interactions influence the "free" end group torsion frequency considerably. Small differences in the distances or angles between the $\mathrm{OH}$ group and the surrounding $\mathrm{N}_{2}$ molecules or the smallness of the basis set used obviously explain why the experimental $\Delta \tau \mathrm{OH}$ of $\tau_{2}$ between species Ia and Ic is $61 \mathrm{~cm}^{-1}$, whereas the calculated difference is only $24 \mathrm{~cm}^{-1}$.

The spectra and the calculations (Table 6) suggest that the trimer end group bands are at $c a$. $500 \mathrm{~cm}^{-1}$. A higher-associate end group band is at $644 \mathrm{~cm}^{-1}$, and the polymer proton donor bands occur at $c a .800 \mathrm{~cm}^{-1}$. Under favourable conditions a relatively sharp $\left(\Delta v_{1 / 2} \quad c a . \quad 10 \mathrm{~cm}^{-1}\right)$ polymer band is seen at $795 \mathrm{~cm}^{-1}$ (superimposed on a much broader band), which indicates that well-defined (probably open) polymer structures exist. This band corresponds to the $\mathrm{WH}$ polymer peak at $3240 \mathrm{~cm}^{-1}$.

As is seen in Fig. 6, the $\tau \mathrm{OH}$ association bands in $\mathrm{N}_{2}$ spectra broaden considerably with increas- 


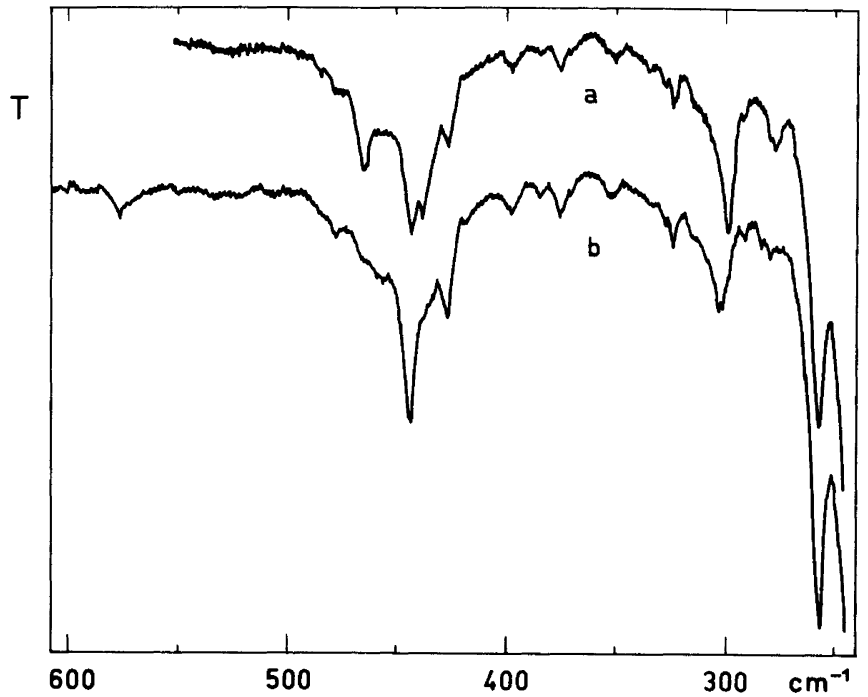

Fig. 7. The $\tau \mathrm{OD}$ region of $\mathrm{CD}_{3} \mathrm{OD}$ in $\mathrm{N}_{2}, \mathrm{M} / \mathrm{A}=100$. a, after deposition; $\mathrm{b}$, after $20 \mathrm{~h}$ in the broad-band IR beam (Nernst irradiation) of the spectrometer.

ing temperature.

The $2 \mathrm{OD}$ region for $\mathrm{CH}_{3} \mathrm{OD}$ and for $\mathrm{CD}_{3} \mathrm{OD}$ (see Fig. 7 and Table 5) is similar to the $\mathrm{TH}$ region of $\mathrm{CH}_{3} \mathrm{OH}$, but the peaks are shifted to lower wavenumbers.

A comparison of the calculated $\tau \mathrm{OH}(\tau \mathrm{OD})$ bands of the associates with the experimental values in $\mathrm{N}_{2}$ is presented in Table 6 . A relatively good correspondence is seen to exist.

We have observed some indication of analogous torsional association fine structure in the spectra of 2-chloroethanol in Ar, and a correspondence between the $\mathrm{WH}$ and $\tau \mathrm{OH}$ dimer fine structures in the spectra of allyl alcohol in $\mathrm{Ar}^{30}$ These findings are exceptional, and the dimers obviously involve specific structures other than

Table 6. Comparison of the calculated and observed wavenumbers $\left(\mathrm{in} \mathrm{cm}^{-1}\right.$ ) of the $\mathrm{OH}$ torsion. E denotes the end group of an open associate.

\begin{tabular}{|c|c|c|c|c|c|c|c|}
\hline \multirow[t]{2}{*}{ Species } & \multirow{2}{*}{$\begin{array}{l}\text { Tors. } \\
\text { at }\end{array}$} & \multicolumn{2}{|c|}{$\mathrm{CH}_{3} \mathrm{OH}$} & \multicolumn{2}{|c|}{$\mathrm{CH}_{3} \mathrm{OD}$} & \multicolumn{2}{|c|}{$\mathrm{CD}_{3} \mathrm{OD}$} \\
\hline & & Calc. & Obs. & Calc. & Obs. & Calc. & Obs. \\
\hline \multirow{3}{*}{$\begin{array}{l}\text { Monom. } \\
\text { Open dim. Ia }\end{array}$} & $\mathrm{O}_{1}$ & 304 & 304 & 241 & 246 & 221 & 239 \\
\hline & $\mathbf{O}_{1}$ & 625 & 623 & 486 & 468 & 455 & 466 \\
\hline & $\mathrm{O}_{2}(\mathrm{E})$ & 385 & 386 & 310 & $\sim 300$ & 284 & 300 \\
\hline \multirow[t]{2}{*}{ Open dim. Ic } & $\mathrm{O}_{1}$ & 597 & 593 & 463 & 446 & 435 & 444 \\
\hline & $\mathrm{O}_{2}(\mathrm{E})$ & 361 & 325 & 290 & 263 & 266 & 258 \\
\hline \multirow[t]{2}{*}{ Linear trim. } & $\mathrm{O}_{1}$ & 731 & $700-750$ & 560 & $520-560$ & 532 & $520-560$ \\
\hline & $\mathrm{O}_{2}$ & $\begin{array}{l}762 \\
420\end{array}$ & 485 & $\begin{array}{l}587 \\
340\end{array}$ & 353 & $\begin{array}{l}557 \\
311\end{array}$ & 352 \\
\hline \multirow[t]{3}{*}{ Cycl. trim. } & $\begin{array}{l}\mathrm{O}_{3}(\mathrm{E}) \\
\mathrm{O}_{1}\end{array}$ & $\begin{array}{l}420 \\
774\end{array}$ & 405 & 544 & & 574 & \\
\hline & $\mathrm{O}_{2}$ & 789 & nossible & $506(6$ & & 580 & \\
\hline & $\mathrm{O}_{3}$ & 747 & & 576 & & 546 & \\
\hline \multirow{3}{*}{$\begin{array}{l}\text { Double accept. } \\
\text { trim. }\end{array}$} & $\mathrm{O}_{1}$ & 567 & & 436 & & 412 & \\
\hline & $\mathrm{O}_{2}(\mathrm{E})$ & 494 & & 406 & & 363 & \\
\hline & $\mathrm{O}_{3}$ & 570 & & 440 & & 414 & \\
\hline
\end{tabular}


trapping site structures.

The $\tau O H$ bands in $\mathrm{CO}$. The quite symmetric monomer band is at $362 \mathrm{~cm}^{-1}$. Its temperature dependence has been discussed previously. ${ }^{10}$

The $\tau \mathrm{OH}$ region of the IR spectrum of a $\mathrm{CO}$ matrix (Fig. 5) is similar to that of an $\mathrm{N}_{2}$ matrix, but the association bands are much weaker and fewer bands are seen; the latter is to be expected, since only two $\mathrm{WH}$ proton donor dimer bands were found. The dimer $D_{1}$ bands are at $400 \mathrm{~cm}^{-1}$ (type $A$ ) and at $450 \mathrm{~cm}^{-1}$ (type $B$ ), and the relatively broad $D_{2}$ bands are at 565 and 635 $\mathrm{cm}^{-1}$, respectively. The sharp proton donor polymer band is at $785 \mathrm{~cm}^{-1}$, and the other proton donor polymer/oligomer bands at $690-750 \mathrm{~cm}^{-1}$. Methanol is less associated in $\mathrm{CO}$ than in $\mathrm{N}_{2}$. The prevailing associates in $\mathrm{CO}$ are dimers and polymers, and thus trimer $\tau \mathrm{OH}$ bands could not be identified with certainty in the spectra.

The other fundamentals. The experimental results seem to indicate that the end group bands of the $\delta \mathrm{OH}$ and $\mathrm{WO}$ vibrations of open associates occur at frequencies lower than the frequency of the monomer band (in accordance with the literature ${ }^{2,31,32}$ ). The calculations predict this effect for $\delta \mathrm{OH}$ but fail in the case of $\downarrow \mathrm{CO}$ (our calculations are too approximate to deal with the coupling of the $8 \mathrm{OH}$ and $\mathrm{VCO}$ modes).

The calculated frequencies for the intermolecular modes of the open dimers (see Table 2) are as good as is the assumption of a common force constant reduction factor. The following comments can, however, be made:

(1). A good PED is obtained for these modes (considerably better than that obtained when the angle $\mathrm{O}_{1} \mathrm{H}_{1} \mathrm{O}_{2}$ is used instead of the angle $\mathrm{C}_{1} \mathrm{O}_{1} \mathrm{O}_{2}$ ). We thus conclude that the coordinates used are a meaningful approximation to the intermolecular normal modes.

(2). The value $222 \mathrm{~cm}^{-1}$ has been reported ${ }^{2}$ for the $\mathrm{H}$-bond stretching fundamental of the dimer in Ar; our calculated value is $192 \mathrm{~cm}^{-1}$.

(3). The frequency for the torsion $\tau_{4}$ around the $\mathrm{O}_{1} \mathrm{O}_{2}$ axis in the dimer is quite low (our calculated value is $18 \mathrm{~cm}^{-1}$ ). The potential is very flat at the minimum, as is shown in Fig. 2.

(4). No bands in $\mathrm{N}_{2}$ or $\mathrm{CO}$ matrix spectra were assigned to intermolecular modes.

IR-induced interconversion of dimers. In the case of 2-substituted ethanols, such as the 2haloethanols, ${ }^{33,26}$ 2-aminoethanol ${ }^{34}$ and 2nitroethanol, ${ }^{35} \mathrm{IR}$ radiation at the $\mathrm{WH}$ frequen- cy causes conformational changes in matrices, i.e., the vibrational excitation energy must have been transferred into torsional states. The coupling between the $\mathrm{OH}$ and torsional states is probably due to interactions with the matrix medium.

In the case of the methanol dimers, it is even more difficult to establish a mechanism for the IR-induced interconversion. The "bonded" $\mathrm{NH}$ vibration of methanol dimer Ia is obviously responsible for the absorption of the IR energy. We assume that the initially excited state goes over into a highly excited state (or states) of torsion $\tau_{1}$, the hydrogen bond $\mathrm{H}_{1} \cdots \mathrm{O}_{2}$ providing the necessary coupling term. In such states the amplitudes of the torsions are large, or there may exist almost free internal rotation. On the other hand, inspection of molecular models shows that relatively small motions of the molecules, or especially of the $\mathrm{OH}$ protons, are needed for the formation of a cyclic dimer. It represents a local energy minimum (at least the planar dimer II can be optimized on the STO-3G level with respect to all intermolecular coordinates), i.e., it plays the role of an unstable intermediate (not transition state) often encountered in chemical kinetics. The cyclic (not necessarily planar) dimer decomposes into species Ic, or back into species Ia. Thus, although the intermediate is unstable, it is stable enough to facilitate the rearrangement of the dimer into species Ic.

Formation of a cyclic dimer from species Ic requires larger molecular motions than its formation from species Ia. This explains why the reverse reaction is slow.

The reaction is slow also in the case of OD methanols, since the deuterium atom is heavier than the hydrogen atom, and the amplitudes of the OD torsions are smaller than those of the corresponding $\mathrm{OH}$ torsions. This would explain also why the D-bonds prevail in the mixed dimers.

On the other hand, it is also possible that the energy pit of the cyclic dimer is relatively deep, and that its rearrangement into open species occurs primarily via tunnelling, which would be faster for a protium atom than for a deuterium atom. This latter mechanism would also explain the preference of D-bonding in the case of the mixed dimer, since the H-bond in the cyclic heterodimer is broken faster than the D-bond.

The energy of the $\mathrm{OH}$ quantum ( $c a .3500$ 
$\mathrm{cm}^{-1}$ ) corresponds to $42 \mathrm{~kJ} \mathrm{~mol}^{-1}$, which is sufficient to dissociate the dimer into monomers. If such a dissociation occurs, it is followed by an immediate recombination inside the site cage, during which a rearrangement of the dimer is possible.

It may be mentioned in this connection that Fredin $e t$ al. $^{36}$ found that, in the case of HOD dimers in $\mathrm{N}_{2}$ matrices, the species $\mathrm{DOH} \cdots \mathrm{O}(\mathrm{D}) \mathrm{H}$ is transformed into HOD $\cdots \mathrm{O}(\mathrm{D}) \mathrm{H}$ in a thermal dark reaction, whereas the reverse reaction takes place due to IR irradiation. Also these processes may involved a cyclic (or bifurcated) intermediate, since it is impossible for the dimer to be broken into monomers in a thermal process under matrix conditions. It has been found, ${ }^{37}$ using a large basis set and including a correlation correction, that a cyclic non-planar water dimer has an energy only ca. $4 \mathrm{~kJ} \mathrm{~mol}^{-1}$ higher than that of the linear dimer.

\section{CONCLUDING REMARKS}

The fine structure of the $\mathrm{OH}$ and $\tau \mathrm{OH}$ dimer bands of methanol in matrices is obviously related to different positions of the two methanol units around the $\mathrm{O} \cdots \mathrm{O}$ axis.

Low-frequency modes such as the $\mathrm{OH}$ or $\mathrm{NH}_{2}$ torsions have been studied very little using matrix infrared spectroscopy. However, such studies seem promising, since at least these torsional frequencies are sensitive to association and other intermolecular influences.

The approximate calculation method in this paper is successful in the case of $\tau \mathrm{OH}$, since the relative frequency changes due to association are then large, and the torsions are only slightly coupled with each other or with other modes. Neglect of the variation (obviously small) of the torsional force constant reduction factor upon association does not lead to serious errors.

In the case of $\mathrm{WH}$ the relative frequency changes due to association are much smaller, and the accompanying changes in the reduction factor cannot be neglected. Our calculations indicate that a coupling term is needed between the $\mathrm{OH}$ and $\mathrm{H}$-bond stretchings in the linear dimers. There are coupling terms of unknown magnitude in the case of the cyclic dimer and all trimers (and of higher associates). For these reasons we did not attempt to predict the $\mathrm{OH}$ wavenumbers for associates other than the linear dimers.

For the first time for an alcohol in matrices, a detailed $\tau \mathrm{OH}$ association fine structure has been found and the bands assigned. The dimer end group $\tau \mathrm{OH}$ band is shifted relatively little from the monomer band, whereas for the higher associates these shifts are considerable.

The calculations and the experimental evidence indicate for $\mathrm{CH}_{3} \mathrm{OH}$ that the torsional dimer bands below $400 \mathrm{~cm}^{-1}$ and the trimer bands near $500 \mathrm{~cm}^{-1}$ are due to end groups of open dimers and trimers, respectively, and that the multimer band at $644 \mathrm{~cm}^{-1}$ is due to end groups of linear or branched species. The presence of cyclic or double acceptor trimers is not completely excluded. However, it can be concluded that the major features of the $\tau \mathrm{OH}$ region of the spectra of methanol in $\mathrm{N}_{2}$ (and also in $\mathrm{CO}$ ) can be explained in terms of non-cyclic associates. As the association proceeds, the alcohol chains become longer (and possibly branch). Raman spectra $^{38}$ and calculations using statistical mechanics ${ }^{22,39}$ give the result that liquid methanol consists primarily of long H-bonded chains.

The cyclic trimer is predicted by the STO-3G calculations to be more stable than "linear" trimers. However, the calculated energy difference was only $8 \mathrm{~kJ} \mathrm{~mol}^{-1}$, the basis used was small, and no supermolecule or dispersion energy corrections were made. Thus, more sophisticated calculations on the trimers are needed. The same applies to the cyclic dimer (the open dimer has been calculated using larger basis sets ${ }^{23}$ ).

On the other hand, although the cyclic trimer may be more stable in vapour than linear trimers, the cyclic species do not necessarily prevail in non-equilibrium systems like matrices.

\section{REFERENCES}

1. Van Thiel, M., Becker, E. D. and Pimentel, G. C. J. Chem. Phys. 27 (1957) 95.

2. Barnes, A. J. and Hallam, H. E. Trans. Faraday Soc. 66 (1970) 1920.

3. Mallinson, P. D. and McKean, D. C. Spectrochim. Acta A 30 (1974) 1133.

4. Serrallach, A., Meyer, R. and Günthard, Hs. H. J. Mol. Spectrosc. 52 (1974) 94.

5. Serrallach, E. and Meyer, R. J. Mol. Spectrosc. 60 (1976) 246.

Acta Chem. Scand. A 37 (1983) No. 4 
6. Burneau, A., Loutellier, A. and Schriver, L. J. Mol. Struct. 61 (1980) 397.

7. Luck, W. A. P. and Schrems, O. J. Mol. Struct. 60 (1980) 333.

8. Schriver, L., Burneau, A. and Perchard, J. P. J. Chem. Phys. In press.

9. Murto, J., Kemppinen, E. and Ovaska, M. Abstract of paper presented at the 3rd International Meeting on Matrix Isolation, Nottingham, England, 20-24th July, 1981.

10. Murto, J. and Ovaska, M. Spectrochim. Acta. A 39 (1983) 149.

11. Stuart, A. V. and Sutherland, G. B. B. M. J. Chem. Phys. 20 (1952) 1977.

12. Pimentel, G. C. and McClellan, A. L. The Hydrogen Bond, Freeman, San Francisco 1960, p. 128.

13. Falk, M. and Whalley, E. J. Chem. Phys. 34 (1961) 1554.

14. Perchard, J. P. and Josien, M.-L. J. Chim. Phys. Phys.-Chim. Biol. 65 (1968) 1856.

15. Rosenberg, M. Sh. and Iogansen, A. V. Opt. Spektrosk. 31 (1971) 711.

16. McDonald, M. P. and Wilford, L. D. R. Spectrochim. Acta A 29 (1973) 1407.

17. Rossarie, J., Gallas, J.-P., Binet, C. and Romanet, R. J. Chim. Phys. Phys.-Chim. Biol. 74 (1977) 202.

18. Murto, J., Kivinen, A., Edelmann, K. and Hassinen, E. Spectrochim. Acta A 31 (1975) 479.

19. Strandman-Long, L. and Murto, J. Spectrochim. Acta A 37 (1981) 643.

20. Del Bene, J. E. J. Chem. Phys. 55 (1971) 4633.

21. Curtiss, L. A. Int. J. Quantum Chem. Symp. 11 (1977) 459.

22. Jorgensen, W. L. J. Chem. Phys. 71 (1979) 5034.

23. Tse, Y.-C., Newton, M. D. and Allen, L. C. Chem. Phys. Lett. 75 (1980) 350.

24. Curtiss, L. A. J. Chem. Phys. 67 (1977) 1144.

25. Brink, G. and Glasser, L. J. Comput. Chem. 2 (1981) 14.

26. Murto, J., Räsänen, M., Aspiala, A. and Homanen, L. J. Mol. Struct. (Theochem.) 92 (1983) 45.

27. Timidei, A. and Zerbi, G. Z. Naturforsch. Teil A 25 (1970) 1729.

28. Blom, C. E., Otto, L. P. and Altona, C. Mol. Phys. 32 (1976) 1137.

29. Cummings, D. L. and Wood, J. L. J. Mol. Struct. 20 (1974) 1.

30. Aspiala, A., Murto, J. and Räsänen, M. Unpublished results.

31. Kabish, G. and Pollmer, K. J. Mol. Struct. 81 (1982) 35.
32. Felder, P. and Günthard, Hs. H. Chem. Phys. Lett. 88 (1982) 473.

33. Pourcin, J., Davidovics, G., Bodot, H., Abouaf-Marguin, L. and Gauthier-Roy, B. Chem. Phys. Lett. 74 (1980) 147.

34. Räsänen, M., Aspiala, A., Homanen, L. and Murto, J. J. Mol. Struct. 96 (1982) 81.

35. Räsänen, M., Aspiala, A. and Murto, J. J Chem. Phys. In press.

36. Fredin, L., Nelander, B. and Ribbegård, G. J. Chem. Phys. 66 (1977) 407.

37. Kistenmacher, H., Lie, G. C., Popkie, H. and Clementi, E. J. Chem. Phys. 61 (1974) 546.

38. Perchard, C. and Perchard, J. P. Chem. Phys. Lett. 27 (1974) 445.

39. Jorgensen, W. L. J. Am. Chem. Soc. 102 (1980) 543; Jorgensen, W. L. and Ibrahim, M. J. Am. Chem. Soc. 104 (1982) 373.

Received September 1, 1982. 